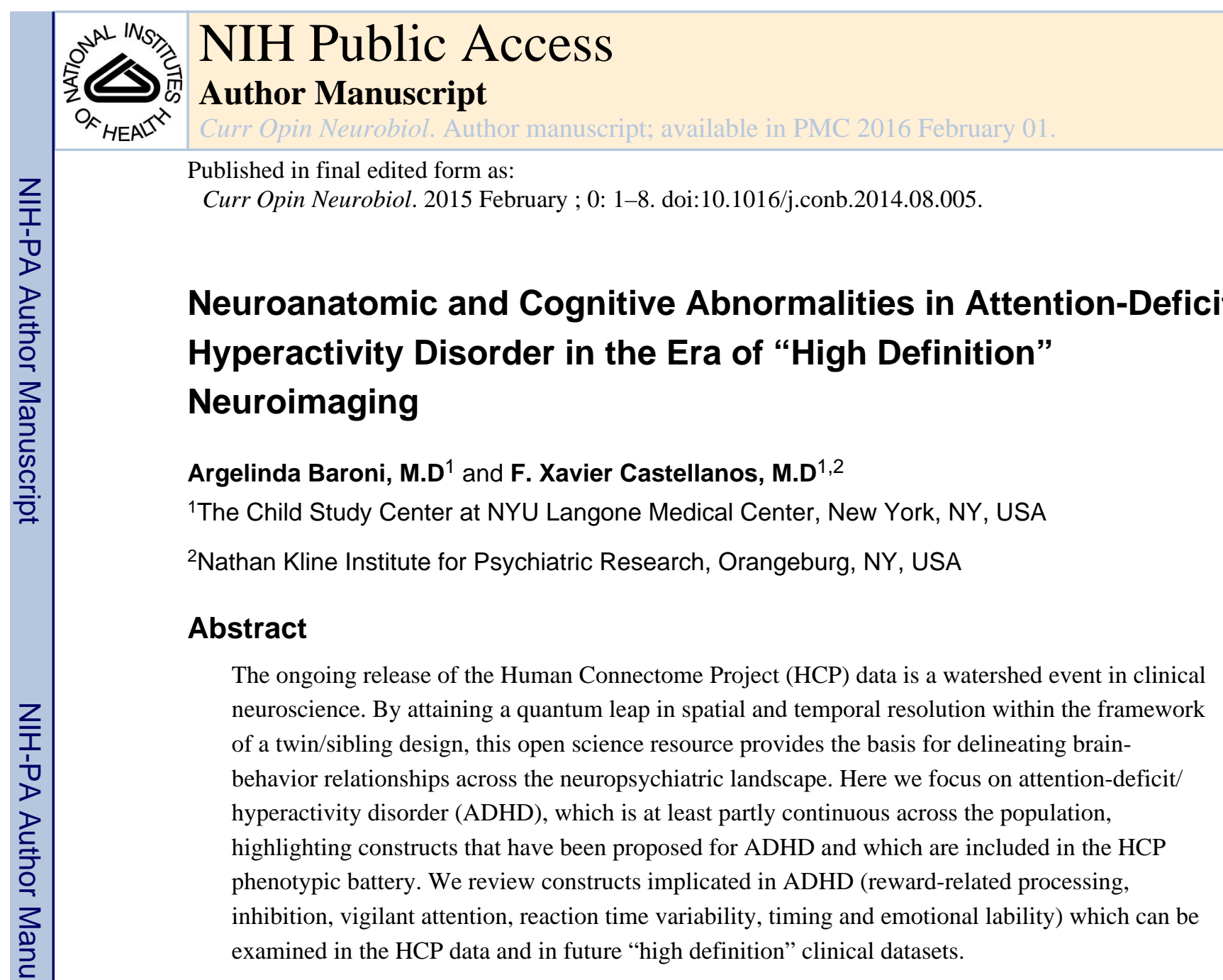

\title{
Introduction
}

Attention-Deficit/Hyperactivity Disorder (ADHD) is one of the most investigated, prevalent [1] and controversial conditions included in the fifth edition of the Diagnostic and Statistical Manual of Mental Disorders (DSM-5) [2]. ADHD is characterized by impairing and developmentally inappropriate levels of hyperactivity/impulsivity or inattention, or both. Like all psychiatric disorders, ADHD is highly heterogeneous, but its validity as a clinical entity is well supported [3] and the test-retest reliability of the DSM-5 criteria was found to be "very good" [4]. Nevertheless, in the absence of biomarkers, the diagnosis relies exclusively on subjective judgments which permit wide variations in prevalence $[5 ; 6]$. Multiple psychological and neuroanatomic models of ADHD have been proposed but most studies in the field have been underpowered [7], which, combined with the limited spatial and temporal resolution of imaging approaches, have only allowed "approximate

(C) 2014 Elsevier Ltd. All rights reserved.

Correspondence to: F. Xavier Castellanos, MD, Center for Neurodevelopmental Disorders, The Child Study Center at NYU Langone Medical Center, One Park Avenue, $7^{\text {th }}$ Floor, New York, NY, 10016 Francisco.Castellanos@ nyumc.org.

Publisher's Disclaimer: This is a PDF file of an unedited manuscript that has been accepted for publication. As a service to our customers we are providing this early version of the manuscript. The manuscript will undergo copyediting, typesetting, and review of the resulting proof before it is published in its final citable form. Please note that during the production process errors may be discovered which could affect the content, and all legal disclaimers that apply to the journal pertain.

Declaration of conflict of interests.

The authors declare no known conflicts of interest. 
replications" [8]. Consequently, established facts regarding the neurobiology of ADHD are lacking.

Fortunately, psychiatric neuroscience is entering the era of "high-definition" magnetic resonance imaging (MRI) as heralded by the launch of the Human Connectome Project (HCP). The design of the HCP and its optimized methods set the stage for discovery of brain-behavior relationships in neurotypical young adults with remarkable anatomic fidelity. We assert that the full prospective sharing of the HCP data can provide templates to achieve more defined insights into the pathophysiology of clinical syndromes such as ADHD. Here, we highlight HCP features that support our optimism and briefly review clues to the neurobiology of ADHD and related conditions that we believe are currently most salient, while identifying some of the opportunities and gaps that remain.

\section{The Human Connectome Project (HCP)}

In 2010, the US National Institutes of Health awarded HCP grants to two consortia, one led by Washington University, University of Minnesota, and Oxford University (the "WUMinn" HCP consortium) and the other by Harvard/MGH and UCLA (now USC) [9]. The MGH-USC consortium is exploiting a prototype 3.0 Tesla scanner with unprecedented gradient strength $(300 \mathrm{mT} / \mathrm{m})$ which is particularly beneficial for diffusion imaging [10]. As of July 22, 2014, data for 45 healthy controls scanned with these novel methods were available for download [http://www.humanconnectomeproject.org/data/].

The WU-Minn consortium was also provided with a prototype 3.0 Tesla scanner (with 100 $\mathrm{mT} / \mathrm{m}$ gradient set) which has been dedicated to scanning 1200 individuals, ages 22-35, composed of 300 pairs of monozygotic or dizygotic twin pairs and their full siblings. The sample was designed to be broadly inclusive, with exclusions largely limited to severe psychiatric, neurological, endocrine or cardiovascular disease. Participants undergo two full days of assessment including four hours of scanning at 3 Tesla; they provide a broad array of phenotypic measures, as shown in Table 1. Wu-Minn HCP data are being made available to the scientific community on a quarterly basis; the 500 subject dataset was released in June 2014.

The HCP has attained multiple incremental advances in imaging resolution, quality and preprocessing that taken together represent a quantum leap in spatial and temporal resolution [9], as illustrated in Figure 1. Beyond providing spectacular resolution, HCP measures overlap substantially with the constructs delineated by the NIMH Research Domain Criteria Project (RDoC) http://www.nimh.nih.gov/research-priorities/rdoc/index.shtml [11]. The explicit rationale for $\mathrm{RDoC}$ is to identify specific neural circuitry underlying typical and atypical behaviors and symptoms, with the goal of directing the search for treatment targets in multiple domains [11]. As shown in Table 1, HCP measures also incorporate many public domain NIH Toolbox instruments [12] and additional measures. The HCP provides an opportunity to perform unbiased data mining for detecting brain-behavior correlates in syndromes such as ADHD which can approximate a full "dimensionome" [13], the complete set of all dimensions relevant to ADHD symptoms. This utility is not limited to ADHD, but ADHD is well-suited to such a whole-brain dimensional approach because its syndromic 
dimensions extend beyond the diagnostic category of ADHD, and because many of its underlying characteristics appear to represent quantitative traits in the general population [14].

\section{Current Clues to the Neurobiology of ADHD}

Magnetic resonance imaging has allowed investigators to relate traditional neurocognitive variables to variations in brain structure and function at the group level. The next generation of studies needs to address brain-behavior relationships at the level of the individual [e.g., 14] to attain clinical utility. Some of the traits that are eventually validated may be included in "the usual suspects," i.e., constructs included in current models. However, the substantial heterogeneity found at every level of analysis and the lack of strong findings to date suggest that dimensions not currently under consideration will also turn out to be relevant. We anticipate that such surprises will emerge from analyses harnessing the survey of potentially relevant traits included in the HCP phenotypic battery [15].

The most studied models of pathophysiology of ADHD involve frontal-striatal-cerebellar circuits, associated with top-down, executive control deficits, and ventral striatal-limbic circuits, associated with bottom-up, reward-related and motivation deficit theories. These models have only partly been supported by structural and functional brain abnormalities in individuals with ADHD but reviewing this voluminous literature is beyond our scope. Instead, we highlight recent research directions, mostly validated by meta-analyses, which hold the greatest promise to support evolving models of pathophysiology. None of the results in the field are currently definitive, so all can benefit from more precisely defined anatomic specification, which can be gleaned from HCP-based methods, combined with statistically well-powered study designs [7].

\section{Inhibition and Attention}

Deficits in inhibiting motor responses and in vigilant attention have long been observed in patients with ADHD and have been linked to the symptom dimensions of hyperactivity/ impulsivity and inattention, respectively. An imaging meta-analysis found distinct functional abnormalities in ADHD in these two domains [16]. For motor inhibition tasks, the most prominent hypoactivations in ADHD were found in right inferior frontal cortex (IFC) extending into the anterior insula, supplementary motor area, anterior cingulate cortex (ACC), caudate and thalamus [16]. By contrast, a range of attentional tasks highlighted ADHD hypoactivation in right dorsolateral prefrontal cortex, putamen, posterior thalamus, caudate tail, and parietal lobe [16]. At least for inhibition tasks, the clinical effects of stimulant medication are also likely mediated by actions on right IFC and anterior insula [17]. These areas are key hubs of the right-lateralized ventral attention network and are also key components of the fronto-parietal central executive network. As reviewed elsewhere [18], the patterns of interplay among these networks are candidate neural substrates for suboptimal behavioral and cognitive functioning in ADHD and related conditions. Improved resolution will provide greater individual subject delineation of these networks and more precisely formulated testable hypotheses. For example, a large community sample of siblings revealed that motor inhibition on the stop task is coheritable with dimensional ratings of ADHD [19]. Determining the heritability of the structural and functional 
connectivity of the right IFC and anterior insula in the HCP sample would set the stage for future studies of affected probands and siblings in ADHD.

Structurally, decreased volume in globus pallidus, putamen, caudate and ACC in ADHD has been confirmed meta-analytically [20], consistent with the dominant model of fronto-striatal dysfunction [18]. Although all studies examined were cross-sectional, putamen/pallidal differences were found in children and ACC differences in adults, suggesting the possibility of developmental effects. Hand-traced group differences in caudate volume were more prominent in studies with greater proportions of untreated patients, suggesting the possibility that stimulant medication may have a normalizing effect [20]. However, a longitudinal examination of basal ganglia surface morphology in ADHD comprising ages 4 to 19 years in 270 patients and 270 age-matched controls failed to find any evidence of stimulant treatment on developmental trajectories [21]. Instead, Shaw and colleagues found the greatest differences in surface area of the ventral striatum. The typically developing controls exhibited continued expansion during the study period, whereas children and adolescents with ADHD showed steady contraction [21]. These results extend the only previous volumetric analysis of the ventral striatum in ADHD, which reported $\sim 25 \%$ smaller volume in 42 children and adolescents with ADHD compared to 42 controls with a large effect size, albeit in mostly previously treated patients [22].

\section{Reward-related Processing}

Morphometric abnormalities in the ventral striatum square well with findings from functional imaging studies of reward anticipation. Abnormal reward sensitivity is considered a core element in ADHD pathophysiology [23] and ventral striatum underlies reward processing in animals and humans. A recent meta-analysis found ventral striatal hyporesponsiveness during reward anticipation in individuals with ADHD, in contrast to the response of neurotypical individuals, questioning the concept of ADHD as a simple extreme of a continuum of normal variability [24]. Showing a similar discontinuity, an fMRI study of neurotypical young adults showed activation in the right ventral and left dorsal striatum during reward anticipation in a classical conditioning paradigm, but no significant effects in the ADHD group. Conversely, upon receipt of rewards, never-medicated adults with ADHD demonstrated significantly greater responses in the ventral striatum bilaterally and in left dorsal striatum relative to controls [25]. Recently emerging resting-state functional MRI (fMRI) methods [26] have also been used to examine ventral striatal functional connectivity. A comparison of 64 neurotypical children and 35 children with ADHD found significantly increased functional connectivity of the ventral striatum and ventromedial prefrontal cortex in the ADHD sample [27], which correlated significantly with a measure of temporal discounting [28], an index of impulsivity [27]. In an aggregated multi-center open science sample of 247 children with ADHD and 304 controls ("the ADHD-200 sample" [29]), Tomasi and Volkow also detected abnormally increased functional connectivity of the ventral striatum and orbitofrontal cortex [30]. Future investigation of ventral striatal and related circuitry should reference HCP data on temporal discounting [15], while keeping in mind the complex nature of intertemporal choices [31;32].

Curr Opin Neurobiol. Author manuscript; available in PMC 2016 February 01. 
In searching for mechanistic explanations of striatal dysfunction, radioligand-based studies have quantified dopamine transporter density in striatum, where it terminates the synaptic effects of dopamine. While patients with ADHD have, on average, higher striatal dopamine transporter density than healthy comparisons [33], the major determinant appears to be prior stimulant treatment. Drug naïve patients with ADHD have been found to have significantly lower dopamine transporter density, while the opposite holds in previously treated patients [33]. Increased striatal dopamine transporter density following stimulant treatment has been confirmed [34].It increased 25\% in 18 never-medicated adults with ADHD who were scanned before and after stimulant treatment for one year, in contrast to no change in 11 healthy controls who were rescanned without medication [34]. These data call into question the assumption that long-term efficacy of stimulants is primarily or exclusively mediated by striatal dopaminergic effects. We believe that neurochemical models of ADHD have been biased towards dopaminergic hypotheses because of investigators' ability to quantify multiple aspect of the striatal dopaminergic system. This "light under the lamppost" bias has persisted despite accumulating evidence implicating the noradrenergic system in modulating prefrontal cortical function [35]. While extending beyond the bounds of the HCP, we anticipate that novel ligands quantifying noradrenergic markers [e.g., 36] will play an increasing role in delineating the neurochemistry of ADHD in adults in the near future. Such approaches are unlikely to be used in children or adolescents, because of ethical protections. Those limitations support an initial focus on young adults with ADHD for studies that will link HCP methods to multimodal MRI combined with positron emission tomography [37].

\section{Vigilant Attention and Reaction Time Variability}

The most frequently used neuropsychological test in ADHD has been the continuous performance test (CPT) which targets deficits in vigilant attention [38;39]. A meta-analysis of vigilant attention studies implicated mainly right-lateralized circuits including dorsomedial, mid- and ventrolateral prefrontal cortex, anterior insula, and parietal areas [40]. As noted above, these areas are frequently linked to ADHD, but CPT fMRI studies in ADHD have been insufficient to support a specific imaging meta-analysis [16]. A metaanalysis of CPT neuropsychological studies found the largest effect sizes for children with ADHD vs. controls in omission errors, a traditional index of deficient vigilance, and reaction time variability (RTV) [41]. The suggestion that RTV should be studied in ADHD [23;42] resonated in the field, as confirmed by a recent meta-analysis of 319 studies in ADHD [43]. This impressive accumulation reported conclusively that both children and adults with ADHD exhibit increased RTV relative to healthy controls, but also found that increased RTV is present in other clinical conditions. Despite the lack of diagnostic specificity, RTV was found to be a stable feature of ADHD and other conditions which is robust to tasks and methods [43]. Increased RTV has become a major focus of recent research [44-51]. For example, building on the known heritability of both ADHD and of RTV, a twin study demonstrated that both ADHD and RTV are genetically related to theta-band phase variability [46]. This illustrates how prioritizing constructs based on their heritability may serve as a filter to accelerate the search for mechanistic clues.

Evidence of increased RTV in ADHD led to the formulation of a mechanistic hypothesis of default network interference [52]. Sonuga-Barke and Castellanos posited that deficient 
regulation of the default network by cognitive control and attention networks underlies intrusions in their interplay that manifest as phasic lapses of attention or in impulsive behaviors. Abnormalities involving the default network in ADHD have been reported repeatedly [e.g., 29;53;54] but this hypothesis needs to be specified with greater resolution, spatially, temporally (i.e., network interactions are dynamic), and by specifying which component processes are expressions of which neural events. The broad range of fMRI tasks and extensive task-free (resting-state) scans in the HCP combined with an even more extensive battery of measures obtained outside the magnet will help delineate the structure and function of the default network and its large-scale partner networks.

\section{Timing}

Converging lines of evidence suggest that multiple aspects of timing-related dysfunction are involved in ADHD [55;56]. Individuals with ADHD present with impairments in motor timing, perceptual timing and temporal foresight, encompassing time intervals from hundreds of milliseconds to tens of seconds, up to years for deficient temporal foresight [55]. The most consistent deficits are found in sensorimotor synchronization, duration discrimination, reproduction, and delay discounting [55]. These deficits are accompanied by functional hypoactivation of areas typically associated with time processing, IFC, dorsolateral prefrontal cortex, supplementary motor area, ACC, basal ganglia, parietal regions and cerebellum [55;56]. Stimulants appear to improve some timing deficits and to normalize hypofunctioning of fronto-striato-cerebellar networks [55;56]. Unfortunately, the HCP phenotyping battery only includes one timing related measure, hypothetical temporal discounting [32].

\section{Emotional Dysregulation}

Emotional dysregulation is not considered a core criterion for ADHD, although it is reemerging as an important contributor to functional outcomes [51;57-64]. This fits with the notion that overlapping circuits underlie both attentional and emotional regulation [39;60]. The HCP is explicitly not a psychiatric sample, but its phenotypic battery includes multiple measures that can tap dimensional variation in mood, psychiatric symptoms, personality traits, social relatedness, psychological well-being, and perceived stress. All such measures could be fruitfully obtained from patients with ADHD-related symptomatology in future HCP-based studies.

\section{Arousal, Sleep and Primary Functions}

For the construct of arousal, both hypo- and hyper-arousal have been proposed and observed in ADHD, but whether the two poles of the arousal spectrum identify alternative neurobiological subtypes, or alternative manifestations of dysfunction in a single regulatory process, remains unknown. Arousal and vigilant attention are closely linked to disorders of sleep, which is related to ADHD in a complex manner [65]. Also worthy of closer reexamination are primary motor and sensory cortical systems which have been largely ignored in ADHD in behavioral studies but which emerge in neuroimaging studies [18]. 


\section{Conclusions}

ADHD is not likely to be determined by any single construct or a fixed combination of the constructs we have enumerated. We have argued that the HCP provides brain-behavior templates that can be applied to dimensional constructs, many of which are likely to be appropriate for ADHD and related conditions. Novel clustering algorithms have documented cognitive heterogeneity in both patients with ADHD and healthy controls [66;67]. Awareness of the extent of phenotypic variation among typically developing individuals further calls into question the traditional approach of contrasting patients and highlyscreened healthy controls [68] and confirms the value of documenting the extent of such variation in non-clinical samples such as the HCP.

The twin/sibling design is particularly appropriate for revealing heritabilities of brainbehavior relationships. Heritable relationships can be prioritized in data-driven analyses, as they are likely to reflect neurobiological processes. Studies of unaffected siblings can also reveal intermediate results that validate dimensional findings in patients while avoiding confounds from treatment history or chronicity of illness. From the perspective of ADHD research, the launching of a Human Pediatric Connectome Project is urgently needed. In the meantime, application of the advances attained by the HCP to young adults with ADHD represents the next best step forward.

\section{Acknowledgements}

This work was partially supported by NIH grant T32MH067763 (FXC) and a neuroscience fellowship from the Leon Levy Foundation (AB).

\section{References and recommended reading}

Papers of particular interest, published within the period of review, have been highlighted as:

* of special interest

** of outstanding interest

1. Willcutt EG. The prevalence of DSM-IV attention-deficit/hyperactivity disorder: a meta-analytic review. Neurotherapeutics. 2012; 9:490-499. [PubMed: 22976615]

2. American Psychiatric Association. Diagnostic and Statistical Manual of Mental Disorders. Fifth Edition. American Psychiatric Association; Washington, D.C.: 2013.

3. Willcutt EG, Nigg JT, Pennington BF, Solanto MV, Rohde LA, Tannock R, Loo SK, Carlson CL, McBurnett K, Lahey BB. Validity of DSM-IV Attention Deficit/Hyperactivity Disorder symptom dimensions and subtypes. J Abnorm Psychol. 2012; 121:991-1010. [PubMed: 22612200]

4. Regier DA, Narrow WE, Clarke DE, Kraemer HC, Kuramoto SJ, Kuhl EA, Kupfer DJ. DSM-5 field trials in the United States and Canada, Part II: test-retest reliability of selected categorical diagnoses. Am J Psychiatry. 2013; 170:59-70. [PubMed: 23111466]

5. Centers for Disease Control. Increasing prevalence of parent-reported attention-deficit/hyperactivity disorder among children --- United States, 2003 and 2007. MMWR Morb Mortal Wkly Rep. 201059:1439-1443.

6. Fulton BD, Scheffler RM, Hinshaw SP, Levine P, Stone S, Brown TT, Modrek S. National variation of ADHD diagnostic prevalence and medication use: health care providers and education policies. Psychiatr Serv. 2009; 60:1075-1083. [PubMed: 19648195] 
7**. Button KS, Ioannidis JP, Mokrysz C, Nosek BA, Flint J, Robinson ES, Munafo MR. Power failure: why small sample size undermines the reliability of neuroscience. Nat Rev Neurosci. 2013; 14:365-376. [PubMed: 23571845] [Based on a systematic review of all neuroscience meta-analyses published in 2011, the authors documented their remarkably low statistical power. This leads to an overestimation of effect sizes and limited reproducibility. Also described is the winner's curse which leads to poor reproducibility, an emerging concern.]

8*. Kapur S, Phillips AG, Insel TR. Why has it taken so long for biological psychiatry to develop clinical tests and what to do about it? Mol Psychiatry. 2012; 17:1174-1179. [PubMed: 22869033] [Perspective on the challenges faced by clinical neuroscience. Suggests that psychiatry should seek to emulate fields that have stratified on the basis of outcomes to delineate homogenous subgroups that can be better targeted therapeutically.]

9. Van Essen DC, Smith SM, Barch DM, Behrens TE, Yacoub E, Ugurbil K. The WU-Minn Human Connectome Project: an overview. Neuroimage. 2013; 80:62-79. [PubMed: 23684880]

10. Setsompop K, Kimmlingen R, Eberlein E, Witzel T, Cohen-Adad J, McNab JA, Keil B, Tisdall MD, Hoecht P, Dietz P, Cauley SF, Tountcheva V, Matschl V, Lenz VH, Heberlein K, Potthast A, Thein H, Van Horn J, Toga A, Schmitt F, Lehne D, Rosen BR, Wedeen V, Wald LL. Pushing the limits of in vivo diffusion MRI for the Human Connectome Project. Neuroimage. 2013; 80:220233. [PubMed: 23707579]

11. Cuthbert BN, Insel TR. Toward new approaches to psychotic disorders: the NIMH Research Domain Criteria project. Schizophr Bull. 2010; 36:1061-1062. [PubMed: 20929969]

12. Gershon RC, Cella D, Fox NA, Havlik RJ, Hendrie HC, Wagster MV. Assessment of neurological and behavioural function: the NIH Toolbox. Lancet Neurol. 2010; 9:138-139. [PubMed: 20129161]

13. Castellanos FX. Toward the dimensionome: parsing reward-related processing in attention-deficit/ hyperactivity disorder. Biol Psychiatry. 2009; 65:5-6. [PubMed: 19064036]

14*. Chabernaud C, Mennes M, Kelly C, Nooner K, Di Martino A, Castellanos FX, Milham MP. Dimensional brain-behavior relationships in children with attention-deficit/hyperactivity disorder. Biol Psychiatry. 2012; 71:434-442. [PubMed: 21974788] [Initial fMRI study illustrating the value of applying both dimensional and categorical approaches to detect brainbehavior relationships among children with ADHD and typically developing children.]

15. Barch DM, Burgess GC, Harms MP, Petersen SE, Schlaggar BL, Corbetta M, Glasser MF, Curtiss S, Dixit S, Feldt C, Nolan D, Bryant E, Hartley T, Footer O, Bjork JM, Poldrack R, Smith S, Johansen-Berg H, Snyder AZ, Van Essen DC. Function in the human connectome: task-fMRI and individual differences in behavior. Neuroimage. 2013; 80:169-189. [PubMed: 23684877]

16*. Hart H, Radua J, Nakao T, Mataix-Cols D, Rubia K. Meta-analysis of functional magnetic resonance imaging studies of inhibition and attention in attention-deficit/hyperactivity disorder: exploring task-specific, stimulant medication, and age effects. JAMA Psychiatry. 2013; 70:185198. [PubMed: 23247506] [Meta-analysis of fMRI studies stratified on the basis of types of task (inhibition and attentional) using a novel regression-based method.]

17. Rubia K, Alegria AA, Cubillo AI, Smith AB, Brammer MJ, Radua J. Effects of stimulants on brain function in attention-deficit/hyperactivity disorder: a systematic review and meta-analysis. Biol Psychiatry. 2013

18. Castellanos FX, Proal E. Large-scale brain systems in ADHD: beyond the prefrontal-striatal model. Trends Cogn Sci. 2012; 16:17-26. [PubMed: 22169776]

19. Crosbie J, Arnold P, Paterson A, Swanson J, Dupuis A, Li X, Shan J, Goodale T, Tam C, Strug LJ, Schachar RJ. Response inhibition and ADHD traits: correlates and heritability in a community sample. J Abnorm Child Psychol. 2013; 41:497-507. [PubMed: 23315233]

20. Frodl T, Skokauskas N. Meta-analysis of structural MRI studies in children and adults with attention deficit hyperactivity disorder indicates treatment effects. Acta Psychiatr Scand. 2012; 125:114-126. [PubMed: 22118249]

21**. Shaw P, De RP, Watson B, Wharton A, Greenstein D, Raznahan A, Sharp W, Lerch JP, Chakravarty MM. Mapping the development of the basal ganglia in children with attentiondeficit/hyperactivity disorder. J Am Acad Child Adolesc Psychiatry. 2014; 53:780-789. [PubMed: 24954827] [Latest in a long line of landmark publications from the longest and largest longitudinal study of brain structure in ADHD. Focused on developmental trajectories in basal 
ganglia morphology in 270 children/adolescents with ADHD and 270 matched typically developing controls. Included an analysis of naturalistic effects of medication use which failed to detect hypothesized medication effects.]

22. Carmona S, Proal E, Hoekzema EA, Gispert JD, Picado M, Moreno I, Soliva JC, Bielsa A, Rovira M, Hilferty J, Bulbena A, Casas M, Tobena A, Vilarroya O. Ventro-striatal reductions underpin symptoms of hyperactivity and impulsivity in attention-deficit/hyperactivity disorder. Biol Psychiatry. 2009; 66:972-977. [PubMed: 19576573]

23. Castellanos FX, Tannock R. Neuroscience of attention-deficit hyperactivity disorder: the search for endophenotypes. Nat Rev Neurosci. 2002; 3:617-628. [PubMed: 12154363]

24*. Plichta MM, Scheres A. Ventral-striatal responsiveness during reward anticipation in ADHD and its relation to trait impulsivity in the healthy population: A meta-analytic review of the fMRI literature. Neurosci Biobehav Rev. 2014; 38:125-134. [PubMed: 23928090] [Meta-analysis of the fMRI studies on reward anticipation in patients with ADHD, tentatively identified opposite patterns of ventral-striatal responsiveness in healthy controls and patients with ADHD, questionning the assumption that ADHD symptoms represent the extreme of normal variability.]

25. Furukawa E, Bado P, Tripp G, Mattos P, Wickens JR, Bramati IE, Alsop B, Ferreira FM, Lima D, Tovar-Moll F, Sergeant JA, Moll J. Abnormal striatal BOLD responses to reward anticipation and reward delivery in ADHD. PLoS ONE. 2014; 9:e89129. [PubMed: 24586543]

26. Craddock RC, Jbabdi S, Yan CG, Vogelstein JT, Castellanos FX, Di Martino A, Kelly C, Heberlein K, Colcombe S, Milham MP. Imaging human connectomes at the macroscale. Nat Med. 2013; 10:524-539.

27*. Costa Dias TG, Wilson VB, Bathula DR, Iyer SP, Mills KL, Thurlow BL, Stevens CA, Musser ED, Carpenter SD, Grayson DS, Mitchell SH, Nigg JT, Fair DA. Reward circuit connectivity relates to delay discounting in children with attention-deficit/hyperactivity disorder. Eur Neuropsychopharmacol. 2013; 23:33-45. [PubMed: 23206930] [Analysis of the relationship between reward processing on a delay discounting task and nucleus accumbens functional connectivity in children with ADHD using resting-state fMRI. Findings were consistent with the hypothesis that atypical signaling between nucleus accumbens and prefrontal cortex leads to impulsive behavior in ADHD.]

28. Scheres A, Tontsch C, Thoeny AL. Steep temporal reward discounting in ADHD-Combined type: acting upon feelings. Psychiatry Res. 2013; 209:207-213. [PubMed: 23347551]

29**. Fair DA, Nigg JT, Iyer S, Bathula D, Mills KL, Dosenbach NU, Schlaggar BL, Mennes M, Gutman D, Bangaru S, Buitelaar JK, Dickstein DP, Di Martino A, Kennedy DN, Kelly C, Luna B, Schweitzer JB, Velanova K, Wang YF, Mostofsky S, Castellanos FX, Milham MP. Distinct neural signatures detected for ADHD subtypes after controlling for micro-movements in resting state functional connectivity MRI data. Front Syst Neurosci. 2013; 6:1-30. Article 80. [Paper by the contributors to the open science ADHD-200 Consortium project used multiple methods to separate signal from micromotion-related artifact. Results in matched subgroups with low motion were able to differentiate the subtypes of ADHD from each other for the first time.]

30. Tomasi D, Volkow ND. Abnormal functional connectivity in children with attention-deficit/ hyperactivity disorder. Biol Psychiatry. 2012; 71:443-450. [PubMed: 22153589]

31. Fassbender C, Houde S, Silver-Balbus S, Ballard K, Kim BK, Rutledge KJ, Dixon JF, Iosif AM, Schweitzer JB, McClure SM. The decimal effect: behavioral and neural bases for a novel influence on intertemporal choice in healthy individuals and in ADHD. J Cogn Neurosci. 2014

32. Scheres A, Sumiya M, Thoeny AL. Studying the relation between temporal reward discounting tasks used in populations with ADHD: a factor analysis. Int J Methods Psychiatr Res. 2010; 19:167-176. [PubMed: 20812292]

33*. Fusar-Poli P, Rubia K, Rossi G, Sartori G, Balottin U. Striatal dopamine transporter alterations in ADHD: pathophysiology or adaptation to psychostimulants? A meta-analysis. Am J Psychiatry. 2012; 169:264-272. [PubMed: 22294258] [First quantitative meta-analysis of striatal dopamine transporter density in adults with ADHD, concluded that striatal dopamine transporter density in ADHD depends on previous psychostimulant exposure, rather than reflecting a primary pathophysiologic trait of ADHD.]

34. Wang GJ, Volkow ND, Wigal T, Kollins SH, Newcorn JH, Telang F, Logan J, Jayne M, Wong CT, Han H, Fowler JS, Zhu W, Swanson JM. Long-term stimulant treatment affects brain 
dopamine transporter level in patients with attention deficit hyperactive disorder. PLoS ONE. 2013; 8:e63023. [PubMed: 23696790]

35. Arnsten AF. Catecholamine influences on dorsolateral prefrontal cortical networks. Biol Psychiatry. 2011; 69:e89-e99. [PubMed: 21489408]

36. Hannestad J, Gallezot JD, Planeta-Wilson B, Lin SF, Williams WA, van Dyck CH, Malison RT, Carson RE, Ding YS. Clinically relevant doses of methylphenidate significantly occupy norepinephrine transporters in humans in vivo. Biol Psychiatry. 2010; 68:854-860. [PubMed: 20691429]

37. Price JC. Molecular brain imaging in the multimodality era. J Cereb Blood Flow Metab. 2012; 32:1377-1392. [PubMed: 22434068]

38. McAvinue LP, Vangkilde S, Johnson KA, Habekost T, Kyllingsbaek S, Bundesen C, Robertson IH. A componential analysis of visual attention in children with ADHD. J Atten Disord. 2012

39. Petersen SE, Posner MI. The attention system of the human brain: 20 years after. Annu Rev Neurosci. 2012; 35:73-89. [PubMed: 22524787]

40. Langner R, Eickhoff SB. Sustaining attention to simple tasks: a meta-analytic review of the neural mechanisms of vigilant attention. Psychol Bull. 2013; 139:870-900. [PubMed: 23163491]

41. Huang-Pollock CL, Karalunas SL, Tam H, Moore AN. Evaluating vigilance deficits in ADHD: a meta-analysis of CPT performance. J Abnorm Psychol. 2012; 121:360-371. [PubMed: 22428793]

42. Castellanos FX, Sonuga-Barke EJS, Scheres A, Di Martino A, Hyde C, Walters JR. Varieties of attention-deficit/hyperactivity disorder-related intra-individual variability. Biol Psychiatry. 2005; 57:1416-1423. [PubMed: 15950016]

43**. Kofler MJ, Rapport MD, Sarver DE, Raiker JS, Orban SA, Friedman LM, Kolomeyer EG. Reaction time variability in ADHD: A meta-analytic review of 319 studies. Clin Psychol Rev. 2013; 33:795-811. [PubMed: 23872284] [This extensive meta-analysis includes 319 studies on reaction time variability (RTV) in children, adolescents, and adults with ADHD. It demonstrates that RTV is not diagnostically specific but does reflect a stable feature of ADHD.]

44. Karalunas SL, Huang-Pollock CL, Nigg JT. Decomposing attention-deficit/hyperactivity disorder (ADHD)-related effects in response speed and variability. Neuropsychology. 2012; 26:684-694. [PubMed: 23106115]

45. Karalunas SL, Geurts HM, Konrad K, Bender S, Nigg JT. Annual Research Review: Reaction time variability in ADHD and autism spectrum disorders: measurement and mechanisms of a proposed trans-diagnostic phenotype. J Child Psychol Psychiatry. 2014

46**. McLoughlin G, Palmer JA, Rijsdijk F, Makeig S. Genetic overlap between evoked frontocentral theta-band phase variability, reaction time variability, and attention-deficit/hyperactivity disorder symptoms in a twin study. Biol Psychiatry. 2014; 75:238-247. [PubMed: 24001472] [First twin study to examine heritability of ADHD symptoms, reaction time variability (RTV), and electroencephalography measures, it showed that theta activity during an Erikson Flanker task is strongly related, phenotypically and genetically, to both ADHD symptoms and RTV.]

47. Antonini TN, Narad ME, Langberg JM, Epstein JN. Behavioral correlates of reaction time variability in children with and without ADHD. Neuropsychology. 2013; 27:201-209. [PubMed: 23527648]

48. Coghill DR, Seth S, Pedroso S, Usala T, Currie J, Gagliano A. Effects of methylphenidate on cognitive functions in children and adolescents with attention-deficit/hyperactivity disorder: evidence from a systematic review and a meta-analysis. Biol Psychiatry. 2013 doi: 10.1016/ j.biopsych.2013.10.005.

49. Feige B, Biscaldi M, Saville CW, Kluckert C, Bender S, Ebner-Priemer U, Hennighausen K, Rauh $\mathrm{R}$, Fleischhaker C, Klein C. On the temporal characteristics of performance variability in attention deficit hyperactivity disorder (ADHD). PLoS ONE. 2013; 8:e69674. [PubMed: 24204553]

50. Kuntsi J, Frazier-Wood AC, Banaschewski T, Gill M, Miranda A, Oades RD, Roeyers H, Rothenberger A, Steinhausen HC, Van der Meere JJ, Faraone SV, Asherson P, Rijsdijk F. Genetic analysis of reaction time variability: room for improvement? Psychol Med. 2013; 43:1323-1333. [PubMed: 22975296]

51*. Sjowall D, Roth L, Lindqvist S, Thorell LB. Multiple deficits in ADHD: executive dysfunction, delay aversion, reaction time variability, and emotional deficits. J Child Psychol Psychiatry. 
2013; 54:619-627. [PubMed: 23061803] [Reasonably powered study examining the relationship between cognitive and emotional deficits in children with ADHD and matched controls. It detected independent effects of reaction time variability and inhibition, but also found that emotional functioning contributed in predicting ADHD status and impairment independently of neuropsychological measures.]

52. Sonuga-Barke EJ, Castellanos FX. Spontaneous attentional fluctuations in impaired states and pathological conditions: A neurobiological hypothesis. Neurosci Biobehav Rev. 2007; 31:977986. [PubMed: 17445893]

53. Elton A, Alcauter S, Gao W. Network connectivity abnormality profile supports a categoricaldimensional hybrid model of ADHD. Hum Brain Mapp. 2014 doi: 10.1002/hbm.22492.

54*. Cortese S, Kelly C, Chabernaud C, Proal E, Di Martino A, Milham MP, Castellanos FX. Towards systems neuroscience of ADHD: A meta-analysis of 55 fMRI studies. Am J Psychiatry. 2012; 169:1038-1055. [PubMed: 22983386] [Meta-analysis of 55 task- based functional fMRI studies conducted on children and adults with ADHD, it found that multiple systems, beyond the classical prefrontal-striatal circuits, are involved in ADHD pathophysiology, including sensorimotor, visual and default networks.]

55*. Noreika V, Falter CM, Rubia K. Timing deficits in attention-deficit/hyperactivity disorder (ADHD): Evidence from neurocognitive and neuroimaging studies. Neuropsychologia. 2013; 51:235-266. [PubMed: 23022430] [Synthesis of studies of timing processing in ADHD, demonstrates that ADHD patients are impaired in motor timing, perceptual timing and temporal foresight. These timing deficits are accompanied by dysfunctions in the inferior fronto-striatocerebellar and fronto-parietal networks, known to mediate timing functions.]

56. Hart H, Radua J, Mataix-Cols D, Rubia K. Meta-analysis of fMRI studies of timing in attentiondeficit hyperactivity disorder (ADHD). Neurosci Biobehav Rev. 2012; 36:2248-2256. [PubMed: 22922163]

57. Hulvershorn LA, Mennes M, Castellanos FX, Di MA, Milham MP, Hummer TA, Roy AK. Abnormal amygdala functional connectivity associated with emotional lability in children with attention-deficit/hyperactivity disorder. J Am Acad Child Adolesc Psychiatry. 2014; 53:351-361. [PubMed: 24565362]

58**. Karalunas SL, Fair D, Musser ED, Aykes K, Iyer SP, Nigg JT. Subtyping attention-deficit/ hyperactivity disorder using temperament dimensions: toward biologically based nosologic criteria. JAMA Psychiatry. 2014 [Study explicitly using an approach based on the Research Domain Criteria Project (RDoC) for classifying patients with ADHD. A total of 437 children with and without ADHD were characterized using temperament dimensions, cardiac physiological measures, fMRI resting state data, and longitudinal outcomes. Three novel types of ADHD were identified based on temperamental measures that were stable over one year and presented unique patterns of physiological responses and resting state connectivity.]

59. Schulz KP, Bedard AC, Fan J, Clerkin SM, Dima D, Newcorn JH, Halperin JM. Emotional bias of cognitive control in adults with childhood attention-deficit/hyperactivity disorder. Neuroimage Clin. 2014; 5:1-9. [PubMed: 24918067]

60*. Shaw P, Stringaris A, Nigg J, Leibenluft E. Emotion dysregulation in attention deficit hyperactivity disorder. Am J Psychiatry. 2014; 171:276-293. [PubMed: 24480998] [Review analyzing the role of emotional dysregulation in ADHD, and its contribution to impairment throughout the lifespan.]

61. Seymour KE, Pescosolido MF, Reidy BL, Galvan T, Kim KL, Young M, Dickstein DP. Emotional face identification in youths with primary bipolar disorder or primary attention-deficit/ hyperactivity disorder. J Am Acad Child Adolesc Psychiatry. 2013; 52:537-546. [PubMed: 23622855]

62. Banaschewski T, Jennen-Steinmetz C, Brandeis D, Buitelaar JK, Kuntsi J, Poustka L, Sergeant JA, Sonuga-Barke EJ, Frazier-Wood AC, Albrecht B, Chen W, Uebel H, Schlotz W, Van der Meere JJ, Gill M, Manor I, Miranda A, Mulas F, Oades RD, Roeyers H, Rothenberger A, Steinhausen HC, Faraone SV, Asherson P. Neuropsychological correlates of emotional lability in children with ADHD. J Child Psychol Psychiatry. 2012; 53:1139-1148. [PubMed: 22882111] 
63. Biederman J, Spencer T, Lomedico A, Day H, Petty CR, Faraone SV. Deficient emotional selfregulation and pediatric attention deficit hyperactivity disorder: a family risk analysis. Psychol Med. 2012; 42:639-646. [PubMed: 21861953]

64. Anastopoulos AD, Smith TF, Garrett ME, Morrissey-Kane E, Schatz NK, Sommer JL, Kollins SH, Ashley-Koch A. Self-regulation of emotion, functional impairment, and comorbidity among children with AD/HD. J Atten Disord. 2011; 15:583-592. [PubMed: 20686097]

65. Owens J, Gruber R, Brown T, Corkum P, Cortese S, O'Brien L, Stein M, Weiss M. Future research directions in sleep and ADHD: report of a consensus working group. J Atten Disord. 2013; 17:550-564. [PubMed: 22982880]

66**. Fair DA, Bathula D, Nikolas MA, Nigg JT. Distinct neuropsychological subgroups in typically developing youth inform heterogeneity in children with ADHD. Proc Natl Acad Sci U S A. 2012; 109:6769-6774. [PubMed: 22474392] [This landmark study characterized neurocognitive domains in both children with ADHD and typically developing children, showing that heterogeneity in cognitive functions is present across groups. Most individuals in both samples could be classified into similar, distinct, neuropsychological profiles.]

67**. Coghill DR, Seth S, Matthews K. A comprehensive assessment of memory, delay aversion, timing, inhibition, decision making and variability in attention deficit hyperactivity disorder: advancing beyond the three-pathway models. Psychol Med. 2013:1-13. [This study confirmed the hypothesis proposed by Fair and co-authors that neurocognitive heterogeneity is present in both children with ADHD and neurotypical children. It included drug naïve boys with ADHD and neurotypical controls that were tested with a battery that comprised the six major cognitive domains relevant for ADHD. While boys with ADHD performed less well than typical boys, these results were driven by a minority of subjects in each domain with, overall, considerable overlap between the two groups.]

68*. Schwartz S, Susser E. The use of well controls: an unhealthy practice in psychiatric research. Psychol Med. 2011; 41:1127-1131. [PubMed: 20810003] [Cautionary note regarding selection of comparison groups.] 


\section{Highlights}

- ADHD is well characterized clinically but its neurobiology remains unclear

- The Human Connectome Project can provide high-definition brain-behavior templates

- Dimensions provided by HCP map well to current neurobiological hypotheses in ADHD

- Application of HD imaging methods to young adults with ADHD holds great promise 


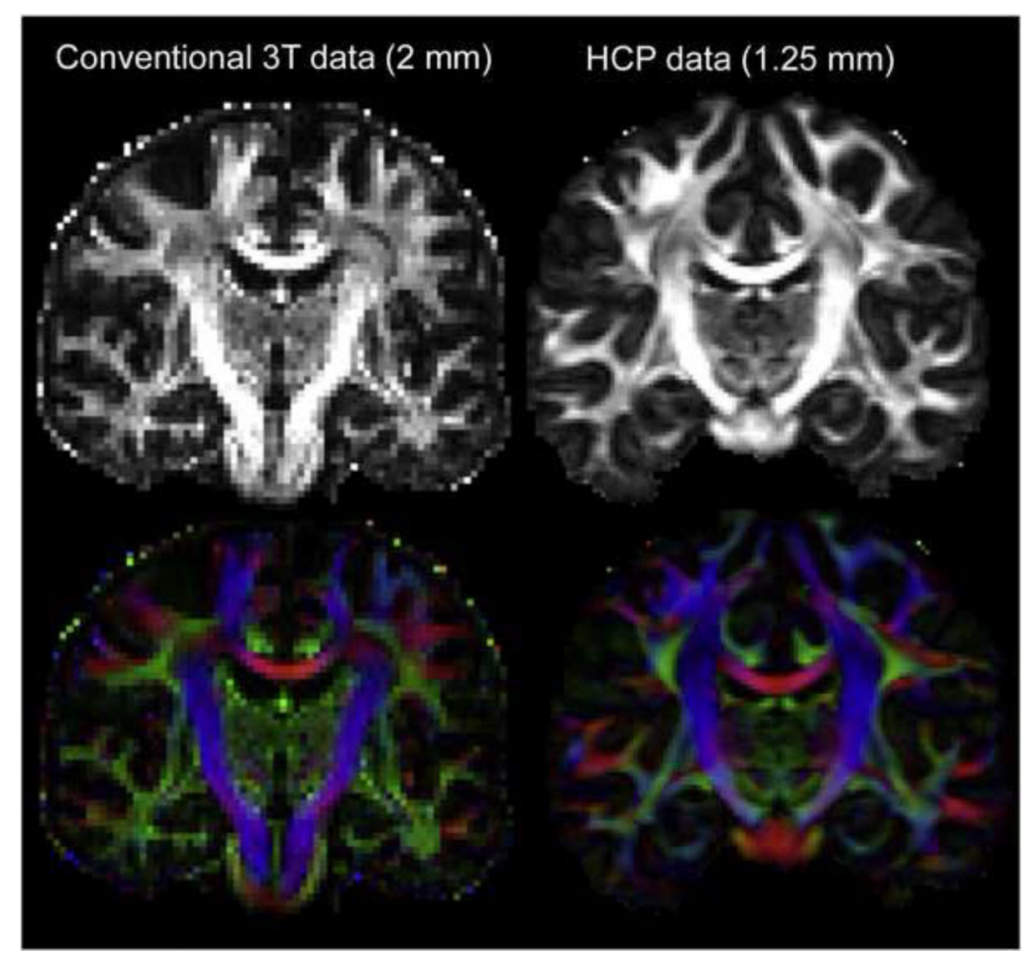

Figure 1.

The improvement in spatial resolution of the Human Connectome Project (HCP) data is illustrated for two separate individuals scanned at conventional "high resolution" (2 mm isotropic voxels) on the left and HCP "high definition" (1.25 mm isotropic voxels) on the right. Reproduced from Van Essen et al. [9] by permission. 


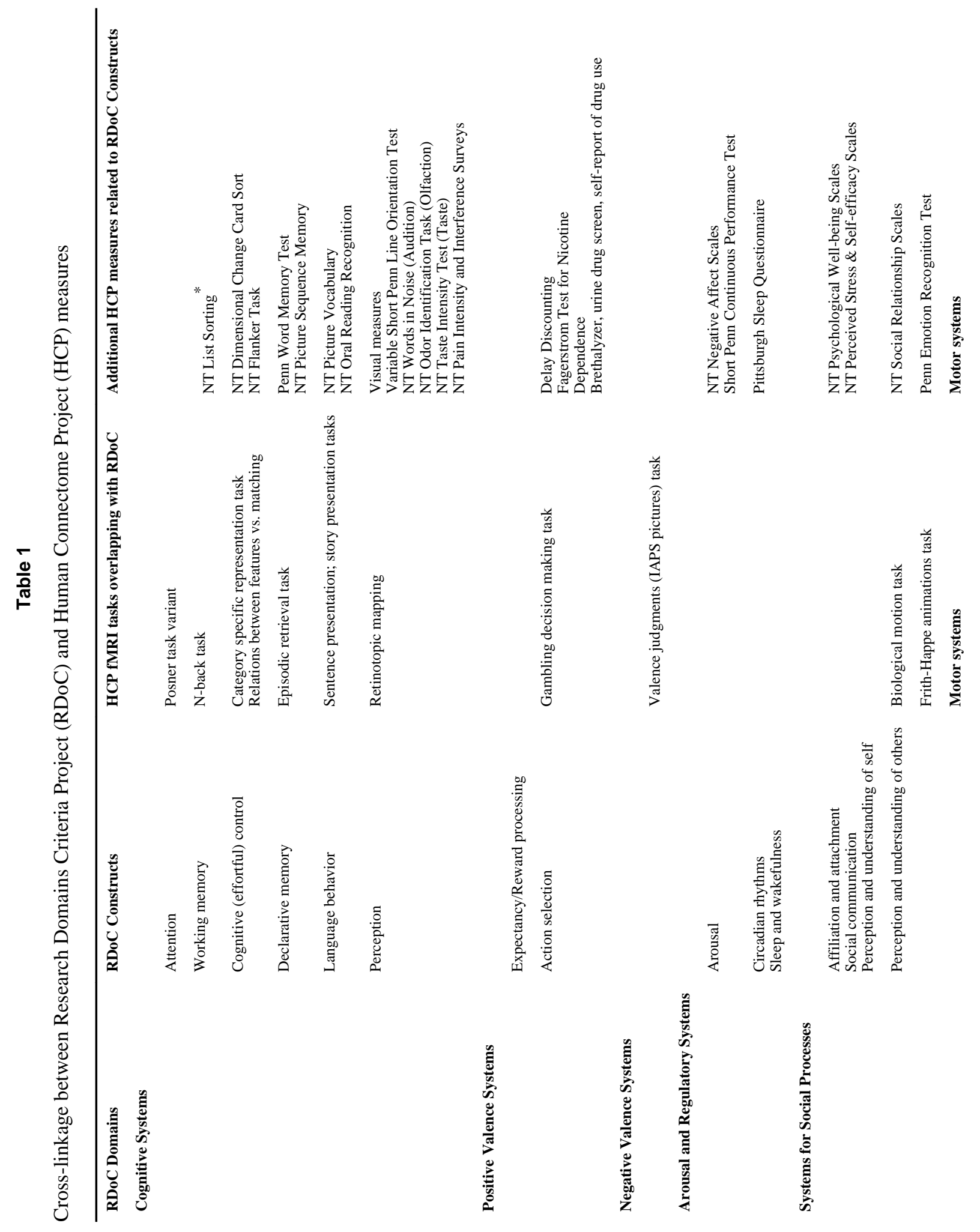

Curr Opin Neurobiol. Author manuscript; available in PMC 2016 February 01. 

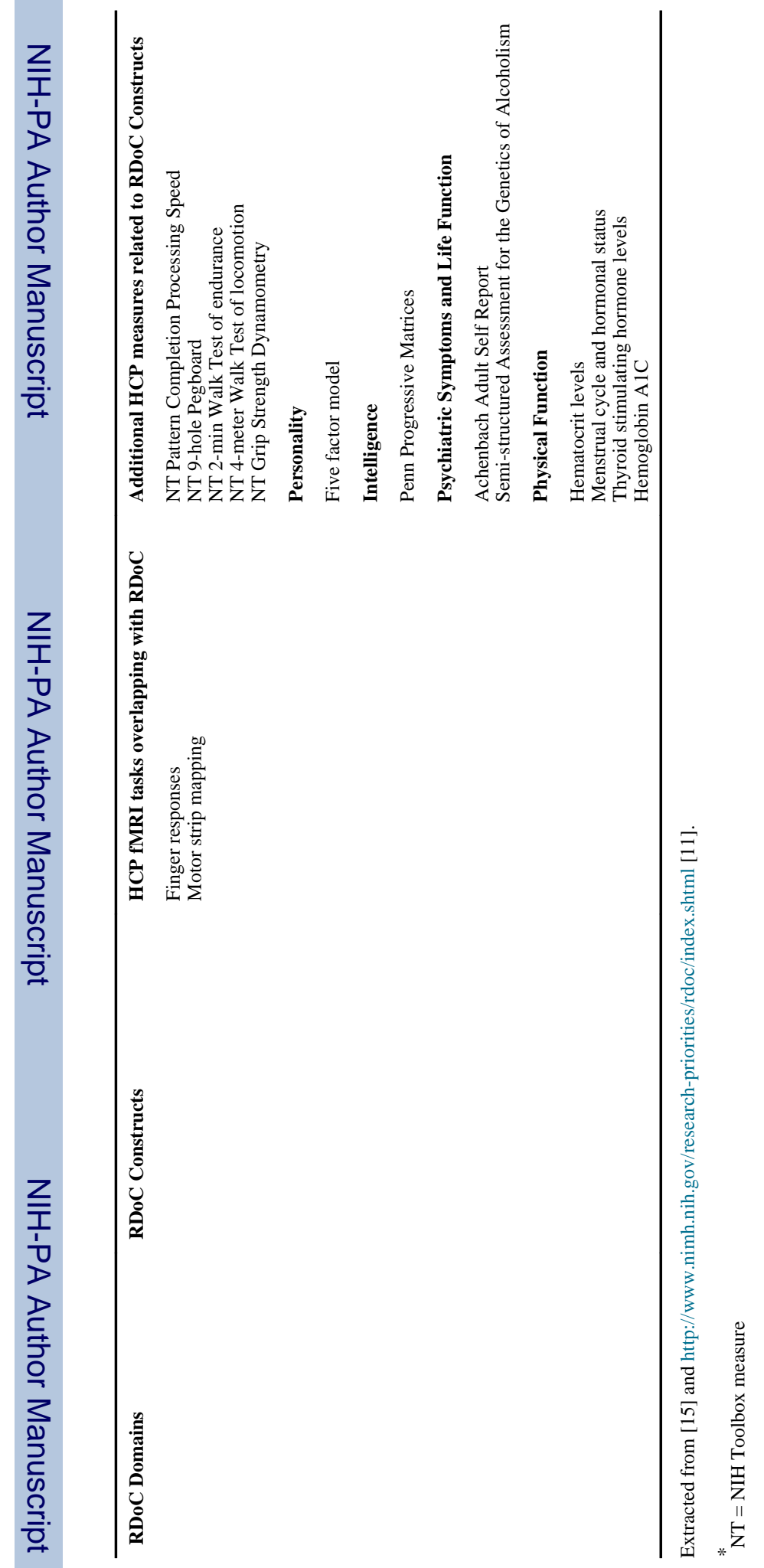

Curr Opin Neurobiol. Author manuscript; available in PMC 2016 February 01. 